\title{
PROCESSO DE FORMAÇÃO DA OPINIÃO DO AUDITOR: UMA ABORDAGEM A PARTIR DA SUFICIÊNCIA E PROPRIEDADE DA PROVA
}

\section{AUDITOR'S OPINION-FORMING PROCESS: AN APPROACH FROM EVIDENCE'S SUFFICIENCY AND PROPRIETY.}

\section{PROCESO DE FORMACIÓN DE LA OPINIÓN DEL AUDITOR: UN ABORDAJE DESDE LA SUFICIENCIA Y PROPIEDAD DE LA PRUEBA}

\author{
ERIVAN FERREIRA BORGES, MSC. \\ Mestre em Administração pela UFRN \\ Coord. da Espec. em Auditoria e Controle Interno da UFRN \\ Professor Efetivo Depto de Ciências Contábeis da UFRN \\ erivanferreiraborges@yahoo.com.br
}

\section{RESUMO}

O trabalho apresenta um ensaio sobre o processo de formação da opinião do auditor, sob uma perspectiva da prova como elemento principal na formação deste processo. Caracteriza a opinião como um ato de poder capaz de influenciar a tomada de decisão por parte de usuários internos e externos. Apresenta os característicos de propriedade e suficiência como qualificadores da prova numa perspectiva construcionista, como elementos fundamentais à formação do juízo a respeito de um dado, fato ou fenômeno passível de investigação. Abordando a teoria de Mautz (1980), propõe um desenho gráfico do processo de auditoria, enfocando os caracteres da prova como fundamento da opinião do auditor. A proposta não se traduz numa tentativa de estabelecer um novo modelo de processo de formação da opinião do autor, mas numa oportunidade de entender este processo no contexto geral dos trabalhos de auditoria realizados dentro das organizações na conjuntura econômica atual.

Palavras-chave: Auditoria; Prova; Propriedade; Suficiência; Poder. 


\section{ABSTRACT}

This paper presents a essay on the auditor's opinion-forming process, under the perspective of having evidence as the main element of this process' formation. Opinion is characterized as a powerful act that is able to influence on decision taking by internal or external users. It presents the traits of propriety and sufficiency as evidence qualifiers in a constructionist view, as fundamental elements to the opinion's formation of data, facts or phenomenon that are to be investigated. By approaching the theory of Mautz (1980), a graphical design of the auditing process was proposed, with emphasis on the evidence characters as essential to the auditor's opinion. The proposal is not translated as an attempt to establish a new model for the author's opinion-forming process, but as an opportunity to understand the process in the general context of auditing works done inside organizations in the current economic conjuncture.

Keywords: Auditing; Evidence; Propriety; Sufficiency; Power.

\section{RESUMEN}

El trabajo presenta un ensayo sobre el proceso de formación de la opinión del auditor, bajo una perspectiva de la prueba como elemento principal en la formación de este proceso. Caracteriza la opinión como un acto de poder capaz de influir en la toma de decisión por parte de usuarios internos y externos. Presenta los característicos de propiedad y suficiencia como calificadores de la prueba en una perspectiva construccionista, como elementos fundamentales a la formación del juicio con respecto a un dato, hecho o fenómeno pasible de averiguación. Abordando la teoría de Mautz (1980), propone un dibujo gráfico del proceso de auditoría, enfocando los caracteres de la prueba como fundamento de la opinión del auditor. La propuesta no se traduce en una tentativa de establecer un nuevo modelo de proceso de formación de la opinión del autor, sino en una oportunidad de entender este proceso en el contexto general de los trabajos de auditoría realizados dentro de las organizaciones en la coyuntura económica actual.

Palabras-Clave: Auditoría; Prueba; Propiedad; Suficiencia; Poder.

\section{INTRODUÇÃO}

A prova auditorial representa um dos grandes desafios do trabalho do auditor. De modo geral os usuários das informações resultantes de um processo de auditoria acreditam que o parecer, resultado final mais conhecido, é a peça mais importante do trabalho. De 
fato, o parecer revela a imagem, a percepção do profissional a respeito do objeto de investigação. Sua completeza não está na quantidade de parágrafos ou mesmo no conceito comum que ele traz nesses parágrafos, mas nos pontos de sustentabilidade aos quais esteja ligado. A prova auditorial representa essa raiz, ou conjunto de raízes que desmistificam o complexo de informações verificáveis, observadas a partir do planejamento inicial do trabaIho, minimizando o conjunto de "dúvidas" do profissional sobre as afirmações e declarações expostas nos demonstrativos contábeis.

O parecer, portanto, deve ser fundamentado em provas consistentes, que possibilitem ao auditor entender que o estado patrimonial relevante não foi ou não será alterado em função dos eventuais problemas ou situações pontuais que não descaracterizam a percepção do usuário da informação contábil. Nesse contexto, destaca-se a necessidade de entender o que significam e como são avaliadas as provas que suportam a opinião expressa no parecer do auditor, especificamente sob dois aspectos relevantes, a suficiência e a propriedade da prova.

Mautz (1980) apresenta um conjunto de elementos identificadores que suportam a formação da opinião do auditor, qualificando cada etapa neste processo de formação da opinião. Este artigo tem como objetivo discutir como se dá o processo de formação da opinião do auditor, como um exercício de poder, a partir do modelo apresentado por Mautz (1980), consubstanciando o valor da prova pela sua suficiência e propriedade.

Optou-se por não abordar as definições e conceituações sobre propriedade e suficiência da prova aceitas na legislação americana e européia, numa tentativa de reforçar a discussão no contexto brasileiro.

Como suporte ao alcance do objetivo principal, apresenta-se um referencial sobre o surgimento e os focos dos trabalhos de auditoria ao longo do tempo, e os pressupostos normativos que delimitam o poder, a propriedade e a suficiência da prova, associando cada conceito à teoria da formação da opinião apontada por Mautz (1980).

\section{AUDITORIA: PRESSUPOSTOS DO SURGIMENTO E FOCO DE ATUAÇÃO}

A auditoria surgiu da necessidade de se obter confirmação da veracidade dos dados contábeis gerados pelas empresas e comerciantes. Alguns acontecimentos sustentam esta afirmação a exemplo do que delimita Franco e Marra (1996), Santi (1988), Almeida (2003), Magalhães, Lunkes e Muller (2001), quando apresentam fatos julgados reais que dão substância ao surgimento desta função profissional, destacando, entre outros elementos, a revolução industrial e conseqüente busca por investimentos, o aparecimento das grandes companhias, e a criação e implantação do imposto de renda na Inglaterra.

A busca por investimentos e a possibilidade de financiar novos empreendimentos, principalmente no seio bancário, catalisou a formação de uma classe de profissionais que passaram a atuar como detentores da confiança destas instituições, na medida em 
que Ihes garantiam a regularidade mínima dos dados apresentados nos demonstrativos contábeis da época como suporte ao crédito solicitado por empresas e artesãos. Estes dados, representados pelos demonstrativos e informações, deviam, naturalmente, receber a atenção de um indivíduo que fosse capaz de entender e perceber o que estava sendo afirmado por meio de números e qualificações expostas em forma de quadros e relatórios. Muitas das informações contidas nos documentos apresentados pelos credores aos eventuais financiadores representavam inovações decorrentes do avanço industrial e tecnológico da época, que repercutiam na maneira contábil de tratá-las. Este cenário possibilita entender que sempre houve uma iminente necessidade de atualização, avanço e adaptação na maneira de elaborar, apresentar e analisar informações de natureza contábil e financeira.

A auditoria, enquanto conjunto de técnicas que possibilita a análise da fidedignidade dos dados apresentados nas demonstrações contábeis, evolui de uma perspectiva meramente escritural para atuar nos processos internos das organizações, conforme Magalhães, Lunkes e Muller (2001). Os autores afirmam que os conceitos

[...] modificam-se conforme as épocas: (a) conceitos mais antigos enfocam a auditoria de registros; (b) conceitos das décadas mais recentes enfocam a auditoria das demonstrações contábeis; (c) conceitos atuais a auditoria das organizações [...] Magalhães, Lunkes e Muller (2001, p. 19).

Na atualidade os trabalhos de auditoria são desenvolvidos em ambientes informatizados e sobre a qualidade operacional e da gestão das entidades. Estes requerem, inclusive, a aplicação de métodos estatísticos na sua execução, buscando possibilitar a formação de uma opinião a partir da confiabilidade dos sistemas e processos, e não apenas nas afirmações explícitas nas demonstrações contábeis, ou seja, o que significa e quanto vale naquele momento. O quadro 1 apresenta uma síntese da evolução dos conceitos e aplicações da auditoria contábil.

Quadro 1 - Evolução dos focos para execução de trabalhos de auditoria

\begin{tabular}{|l|l|l|}
\hline PERSPECTIVA & $\begin{array}{c}\text { BASE PRINCIPAL DE } \\
\text { EXAME }\end{array}$ & PROFUNDIDADE \\
\hline ESCRITURAL & $\begin{array}{l}\text { REGISTROS E } \\
\text { SALDOS }\end{array}$ & $\begin{array}{l}\text { REALIZAÇÃO DE EXAMES COM } \\
\text { CARACTERÍSTICAS INTEGRAIS }\end{array}$ \\
\hline DEMONSTRAÇÕES & $\begin{array}{l}\text { REGISTROS E } \\
\text { SALDOS }\end{array}$ & $\begin{array}{l}\text { EXAME INTEGRAL DOS SALDOS } \\
\text { E APLICAÇÃO DE TÉCNICAS DE } \\
\text { AMOSTRAGENS SOBRE TENDÊNCIAS }\end{array}$ \\
\hline ORGANIZAÇÕES & $\begin{array}{l}\text { PROCESSOS, } \\
\text { REGISTROS E SALDOS }\end{array}$ & $\begin{array}{l}\text { APLICAÇÃO INTEGRAL DE TÉCNICAS DE } \\
\text { AMOSTRAGEM }\end{array}$ \\
\hline
\end{tabular}

Fonte: elaborado pelo autor a partir de Magalhães, Lunkes e Muller (2001). 
A utilização de qualquer das perspectivas acima exige um nível de aprofundamento na execução do trabalho que possibilite ao profissional a formação de uma opinião tecnicamente adequada sobre o que venha a examinar, de maneira a afastá-lo do risco de emitir um parecer equivocado. O aprofundamento, conclui-se, engloba não somente a aplicação de procedimentos, mas o resultado de uma análise sobre a possibilidade de incorrer em riscos, inclusive os decorrentes de mudanças nos cenários econômicos e governamentais.

$\mathrm{O}$ crescimento dos interesses comerciais e das necessidades de mercados, incluindo a busca de garantias que minimizassem perdas e contingências, provocou um verdadeiro avanço na maneira de se fazer negócio desde então (revolução industrial). Até os dias atuais este avanço permanece como uma necessidade latente a fim de consubstanciar dois pontos básicos discutidos numa ciência social aplicada: sua aplicabilidade e adaptação.

Apesar dos conceitos quanto às formas de auditoria expostos por Franco e Marra (1996) e Magalhães, Lunkes e Muller (2001), nos aspectos de aplicabilidade e adaptação, é consenso entre esses autores e órgãos normativos como o Conselho Federal de Contabilidade - CFC e a própria Comissão de Valores Mobiliários - CVM que a realização de um trabalho de auditoria geral e integral é inviável sob diversos aspectos, como eficiência, eficácia e custos, que neste trabalho não são abordados. Quanto à adaptação, esta representa uma condição indispensável para alcance da eficiência e eficácia dos trabalhos, tendo, na aplicação de técnicas de amostragem e na obtenção de meios genéricos que fundamentem a opinião, exemplos que materializam esta condição.

Como se vê, formar uma opinião diante do volume de informações geradas pelas organizações exige do profissional um nível de preparação e conseqüente cognição sobre o objeto de exame. A preparação profissional é exposta por sua capacidade de conhecer e aplicar as normais técnicas e profissionais, e sua cognição a esse respeito de saber identificar, por meio de um processo lógico, que elementos corroboram este convencimento (MAUTZ, 1980).

A formação da opinião, portanto, torna-se complexa diante do volume de informações geradas no seio das organizações, quando são analisadas em conjunto com fatores externos. Neste contexto, o processo de formação da opinião torna-se objeto de discussão nos trabalhos de auditoria, pois configura-se num exercício de poder capaz de influenciar usuários na tomada de decisão, conforme ilustrado na figura 1, que sintetiza a execução e conclusão dos trabalhos do auditor.

Figura 1 - Opinião como exercício de poder.

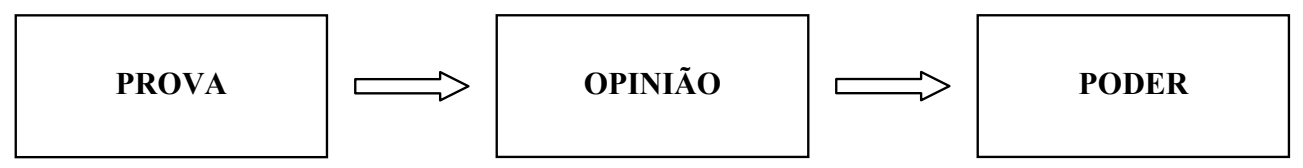

Fonte: Elaborado pelo autor 


\section{repec}

Na figura 1 omite-se, propositalmente, o planejamento como elemento inicial necessário à demonstração do processo auditorial completo; por não se constituir objeto deste estudo a sua discussão em completude, apenas se apresenta a prova como pedra angular, destacando-se sua suficiência e propriedade, como elementos principais.

\section{OPINIÃO E PARECER E O EXERCÍCIO DE PODER}

O conceito de poder, amplamente discutido na literatura organizacional, segundo Hall (2004), representa um ato que só pode ser utilizado ou exercido quando há agentes ativos e passivos que o qualifiquem. O poder não tem significado sem o seu pleno exercício, que depende da interação entre dois pólos: de ação e reação. Deste modo, sua existência só é percebida diante da resposta ao estímulo, ou seja, do seu exercício. Assim, dois fatores importantes são evidenciados na definição de ato que externe o exercício de poder, sua utilização e o seu efetivo exercício.

Entendendo o poder como algo que requer estímulo, comportamentos e situações do indivíduo sobre o qual ele é utilizado ou exercido, depreende-se que a sua existência está ligada à resposta, como dito antes. Este pensamento é expresso por Emerson apud Hall (2004), quando afirma que as relações de poder acarretam dependências mútuas entre indivíduos, um necessitando do outro.

Entre as várias abordagens sobre o conceito de poder, destacam-se as tipologias desenhadas por Weber (1947), que faz uma distinção entre poder e autoridade, caracterizando esta sob os aspectos racional legal, carismático e tradicional. Sua abordagem define poder como elemento de dominação, uma visão aderente ao pensamento marxista, que trata da propriedade e do controle sobre os meios de produção. Para Weber, além dos aspectos apontados por Marx, o conhecimento e a especialização são bases e fontes de poder que podem ser utilizadas ou exercidas, visão que encontra força nos trabalhos de Morgan (1996). Sobre o exercício preconiza Morgan (1996) que:

A autoridade burocrática ou racional legal aparece quando as pessoas insistem que o exercício do poder depende da correta aplicação de regras formais e procedimentos. Aqueles que exercem a autoridade burocrática devem ganhar os seus direitos de poder..., demonstrando qualificações profissionais ou técnicas quando atuando em uma meritocracia. (MORGAN, 1996, p. 165).

Mintzberg (1992) delimita em seus trabalhos que existem cinco formas de exercício de poder, também consoante ao pensamento de Weber (1947). Entre estas formas, destacam-se a dependência da organização em controlar um recurso, a dependência de uma habilidade técnica, a dependência de um corpo de conhecimento que seja importante para a organização, as prerrogativas legais e o acesso dos agentes a uma das quatro fontes de poder citadas. 
Segundo Souza, Bianco e Machado (2005), as três primeiras fontes de poder definidas por Mintzberg têm uma relação direta com alguma debilidade que a organização possui e que, para suprir esta deficiência, depende de alguém para fornecer tais "recursos". Nos trabalhos de auditoria isso pode ser exemplificado pelo domínio que o auditor tem sobre o conhecimento dos processos contábeis e de controles internos. As outras duas fontes de poder não têm nenhuma relação com uma possível dependência que a organização possa ter delas.

Para Mintzberg (1992) o poder pode ser caracterizado como um conjunto de normas, regras, e não pode ser alterado, senão com o objetivo de ratificá-lo, consolidá-lo nesta perspectiva. Qualquer tentativa de exercício por outra forma não possui a legitimidade, senão pelo cumprimento de regras, de normas.

Foucault (2007) tem uma visão mais ampla do significado de poder. Seu pensamento baseia-se na idéia de que o poder não é algo que possibilita a um indivíduo ou grupo específico um domínio sobre os demais em função apenas de uma característica ou conhecimento, mas o resultado das relações existentes entre os indivíduos que fazem parte de um campo social. Para o filósofo o poder não tem uma origem pré-determinada e deve ser compreendido como resultado de um conjunto de relações. Portanto, não é algo que se possua, que se domine, que se adquira ou que se deixe escapar. Não é uma propriedade que possa ser possuída, mas exercido.

O poder funciona e se exerce em rede. Nas suas malhas os indivíduos não só circulam mas estão sempre em posição de exercer este poder e de sofrer sua ação; nunca são o alvo inerte ou consentido do poder, são sempre centros de transmissão. (FOUCAULT, 2007, p. 183).

Souza, Bianco e Machado (2005), Foucault não cria conceitos fixos, cristalizados, imóveis sobre o poder como outros autores organizacionais, quando abordam a temática. Para eles, Foucault não desenvolve uma teoria sobre o poder, mas uma analítica do poder. Esses autores delimitam que para Foucault uma ação, ainda que praticada individualmente, traduz uma ação coletiva, pois nenhuma atitude pode ser considerada como individual porque sempre existirá um conjunto de forças interagindo em um ambiente coletivo, constituindo este poder e dando-lhe um grau de imprevisibilidade.

A apresentação do pensamento de Foucault é feita para delimitar que em certos aspectos, principalmente aqueles ligados aos trabalhos de campo desenvolvidos pelo auditor, podem assumir características apontadas pelo autor, quando este fala da imprevisibilidade de uma ação. A opinião do auditor sempre estará amparada pelas confirmações e descobertas inerentes aos testes que este aplica nas fases que compõem o seu trabalho. O domínio da técnica reforça a idéia de autores como Weber (1947) e Mintzberg (1992), no que tange às confirmações, sem maiores aprofundamentos de testes e procedimentos, dos cenários inicialmente previstos no planejamento, indicando que o trabalho 
alcançou um grau de precisão em função do domínio das técnicas contábeis e do conhecimento dos sistemas de controle internos da organização eventualmente auditada pelo profissional. Do mesmo modo, o resultado do trabalho, revestido em forma de opinião, encontra ponto na imprevisibilidade inerente as eventuais descobertas não planejadas, reforçando a analítica de Foucault.

Esses pólos de associação apenas reforçam a complexidade da formação de uma opinião em auditoria, tratada aqui como um exercício de poder. O entendimento dos elementos conseqüentes de um trabalho que apresente a necessidade de aprofundar exames e procedimentos de auditoria gera um grau de subjetividade que só a experiência profissional do auditor poderá resolver e fazer com que esse profissional obtenha o meIhor juízo sobre os fatos descobertos inicialmente não planejados. Essa subjetividade está presente no conjunto de normas profissionais editadas pelo CFC, a exemplo da NBC T 11.6 (Relevância), NBC T 11.10 (Continuidade Normal das Atividades), NBC T 11.13 (Estimativas Contábeis), NBC T 11.15 (Contingências), NBC T 11-IT 03 (Fraude e Erro), entre outras.

Por tal lado, e com maior visibilidade presumida, o domínio das técnicas necessárias à realização de um trabalho de auditoria, traduz o pensamento dos autores que defendem que entre os elementos de poder destacam-se o domínio do conhecimento e a especialização. A subjetividade presente na opinião do auditor é de seu exclusivo conhecimento, pois sua opinião deve ser fundamentada em provas consistentes, que possibilitem, não só ao auditor, mas aos usuários dessa opinião, aceitar sua especialidade como uma verdade.

Assim, é importante destacar que o conhecimento e o domínio da especialidade contábil se demonstram, inicialmente, como os elementos que fundamentam o exercício de poder, sendo esta a perspectiva adotada no presente trabalho.

\subsection{Auditoria como exercício de poder}

A utilização do conceito de poder discutido no meio organizacional encontra ponto de associação à teoria da prova e formação da opinião do auditor na medida em que existe uma série de fatores que qualificam este tipo de trabalho. A auditoria, como uma especialidade, um conhecimento, vem a ser uma das formas de utilizar e/ou exercer o poder, destacando-se, a partir de alguns pressupostos, que:

- É uma especialidade profissional com normas e regras próprias, e, portanto, de difícil assimilação, o que por si só dá um status quo (poder) a quem a exerce;

- É uma atividade necessária em diversos ramos empresarias que provoca uma submissão imediata e instantânea de quem está obrigado a contratar tal tipo de serviço; ou seja, gera dependência; 
- O seu exercício está ligado ao conceito de independência profissional, de forma institucionalizada, descaracterizando quaisquer tipos de influência do agente passivo (auditado) sobre o ativo (auditor);

- Contempla a aplicação de procedimentos metodológicos que vão além das informações prestadas ao contratante, na medida em que são necessários à formação de uma opinião isenta e independente.

O conhecimento e o domínio de uma técnica profissional constituem um diferencial na geração de informações que, quando utilizadas, servem para catalisar um processo decisório por parte do usuário. Falando do controle do conhecimento e da informação como fonte de poder, Morgan (1996, p. 173) delimita que o indivíduo controlando esses recursoschave pode sistematicamente influenciar a definição das situações organizacionais e criar padrões de dependência.

A contabilidade tem como objetivo principal a geração de informações úteis à tomada de decisão, não sendo diferente em relação à auditoria. Esta abordagem encontra ponto no pensamento de Dizard apud Silveira (2000), que entende o domínio de uma informação como exercício de poder, ou mais que isso, segundo suas palavras, um fator multiplicador e também medida de avaliação deste poder.

Sobre este ponto, delimita Morgan (1996):

Um aspecto final do poder do especialista relaciona-se ao uso do conhecimento e da especialização como meio de legitimar aquilo que alguém deseja fazer. O especialista, frequentemente carrega uma áurea de autoridade e poder que poder acrescentar considerável peso a decisão que permanece suspensa. (MORGAN, 1996, p. 174).

Durante o processo de formação de sua opinião, o auditor possui o poder racional legal conferido por seu contratante, que, teoricamente, vem a se submeter ao que este profissional apresentar como plano de trabalho e execução. Seu ceticismo e curiosidade, alheios aos interesses individuais e pessoais do cliente, devem proporcionar a formação de um conceito, seja positivo ou negativo, a respeito das demonstrações ou estados patrimoniais pertencentes a quem o contratou.

Esta capacidade é tecnicamente conceituada como competência profissional, que representa o nível de preparação técnico profissional e a aderência às normas e preceitos legais, e sua habilidade de preparar relatórios claros e completos, com recomendações apropriadas para análise e discussão, conforme apontam Lisboa et al (1997).

Sá (2001, p. 192) divide a competência em dois aspectos: potencial e funcional. Sob o aspecto potencial, afirma que “... é o conhecimento acumulado por um indivíduo, suficiente para o desempenho eficaz de uma tarefa". Sobre o aspecto 


\section{repec}

funcional, conceitua-o como o exercício do conhecimento de forma adequada e pertinente a um trabalho.

Ferreira (1999, p. 512) define competência como sendo a "qualidade de quem é capaz de apreciar e resolver certo assunto, fazer determinada coisa, capacidade, habilidade, aptidão, idoneidade".

Borges (2005) entende que os conceitos apresentados denotam preparação técnica do profissional e conseqüente aderência a normas legais dos órgãos fiscais e de classe, a fim de se executar uma tarefa de forma eficiente e com eficácia. Estes identificadores se revestem numa especialidade exigida na Norma Brasileira de Contabilidade Profissional - NBC P 1, emitida pelo Conselho Federal de Contabilidade - CFC, que estabelece no seu preâmbulo:

1.1.1 - O contador, na função de auditor independente, deve manter seu nível de competência profissional pelo conhecimento atualizado dos Princípios Fundamentais de Contabilidade e das Normas Brasileiras de Contabilidade, das técnicas contábeis, especialmente na área de auditoria, da legislação inerente à profissão, dos conceitos e técnicas administrativas e da legislação específica aplicável à entidade auditada. (CFC, 2006)

A competência exigida pelas normas e pelo próprio código de ética da profissão contábil é condição indispensável à independência profissional e ao nível de confiabilidade da informação prestada pelo auditor. Sua permanência no mercado, certamente, será conseqüente do poder de multiplicação resultante das suas opiniões enquanto entendidas como úteis, que também servirão como medidas de avaliação do seu trabalho, numa acepção ao apontado por Dizard apud Silveira (2000) sobre o efeito multiplicador e avaliador do que seja poder.

\section{PROPRIEDADE E SUFICIÊNCIA DA PROVA}

As abordagens apresentadas a seguir são embasadas, principalmente, nos aspectos normativos emanados do Conselho Federal de Contabilidade - CFC, por meio das Normas Brasileiras de Contabilidade Técnicas - NBC Ts, aplicáveis ao trabalho de auditoria. A opção por essa abordagem é uma tentativa de discutir a suficiência e propriedade da prova a partir das práticas contábeis adotadas no Brasil, ou seja, no contexto socioeconômico nacional, na cultura contábil local.

\subsection{Propriedade}

Na realização dos trabalhos, os profissionais definem, no seu planejamento e conjunto de programas, os objetivos a serem alcançados em cada exame. Um objetivo comum na verificação de ativos e passivos é a posse e a propriedade de bens, direitos e obrigações, 
conforme apontam Boynton, Johnson e Kell (2002); Attie (1998); Franco e Marra (1996); Mautz (1980); Almeida (2003).

A discussão que leva em conta o conceito de propriedade em auditoria pode ser inferida sob de dois aspectos principais: a propriedade enquanto domínio, posse; e enquanto aderência, confiabilidade.

O primeiro identifica se o objeto da auditoria pertence à empresa auditada e reflete com fidedignidade suas posses legais. A legalidade parte do pressuposto de que objetos semelhantes pertencentes a terceiros podem servir como elemento de prova perceptível aos olhos, mas não à propriedade propriamente dita: possuir e ter prova legal dessa posse. A aplicação de testes substantivos e de procedimentos de exame e investigação de ativos exemplifica esta característica.

O segundo aspecto caracteriza-se por sua subjetividade, pois envolve elementos normativos e de julgamento profissional, dando-lhe esta condição. A NBC T 1 que trata das características da informação contábil delimita, entre outros pontos, a necessidade de que toda informação de natureza contábil deve possuir um nível de confiabilidade, de aceitação:

A confiabilidade é um atributo que faz com que o usuário aceite a informação contábil e a utilize como base de decisões, configurando, pois, elemento essencial na relação entre aquele e a própria informação.

1.4.2 - A confiabilidade da informação fundamenta-se na veracidade, completeza e pertinência do seu conteúdo. (CFC, 2006)

A norma trata da veracidade, completeza e pertinência, numa alusão à possibilidade de determinado fato, contexto ou existência material não possuir o elemento de propriedade identificado. Essa tríade apresentada na norma traduz o objeto a ser investigado pelo auditor durante o seu trabalho. A existência de elementos que descaracterizem a obediência a aspectos legais, não somente aos princípios contábeis, mas a de julgamentos que possibilitem alguma certeza e previsão, torna a informação, dado ou atributo inverídicos, e pode descaracterizar sua propriedade. De igual modo, e sem caráter excludente, os fundamentos de completeza e pertinência precisam estar revelados, seja na compreensão relativa do que o fato, contexto ou existência material quer dizer ou divulgar.

É importante destacar que o principal objetivo do auditor é colher elementos suficientes que Ihe possibilitem ter relativa certeza sobre o que é ou não afirmado pelo contratante detentor (gestor) do objeto de exame, seja uma organização, uma conta, um processo. Portanto, a verificação da propriedade alcança ênfase numa perspectiva de aproximação, de relativa realidade e realização. Esta afirmação encontra ponto nas NBC T 11.6 (Relevância), NBCT 11.10 (Continuidade Normal das Atividades), NBCT 11.13 (Estimativas 
Contábeis), NBCT 11.15 (Contingências), NBCT 11-IT 03 (Fraude e Erro), pois suportam a idéia de julgamento, e transferem ao auditor a responsabilidade de entender uma ou outra restrição como capaz ou não de influenciar sua opinião.

Esta qualidade especial da informação (propriedade) - decorrente da interpretação da prova - materializa a subjetividade antes referenciada. Julgar uma informação é condição de poder concedida racionalmente por quem contrata, e conquistada pelo profissional por suas prerrogativas e pelo domínio das técnicas aplicáveis no trabalho, reforçando o pensamento de Morgan (1996). A propriedade, portanto, não é uma mera suposição decorrente da contingência do trabalho ou da situação momentânea, mas antes um conceito, um valor construído pela associação de alguns fatores, que entre estes podem citados:

- O conhecimento prévio das atividades desenvolvidas pelo contratante;

- O nível de participação de cada atividade sobre a estrutura patrimonial;

- O conhecimento das legislações e normas inerentes às atividades desenvolvidas pelo contratante;

- O conhecimento detalhado dos sistemas que suportam a geração de informação;

- O nível de preparação técnica e acadêmica do auditor;

- Tempo e atuação e experiências passadas;

- O nível de independência e introjeção psicológica do auditor; e,

- Outros apontados pela NBCT 11 e respectivas interpretações técnicas emanadas do CFC.

Estes fatores não são infinitos. Parece contradição, mas a afirmação decorre justamente da especificidade e do ambiente de aplicação de cada trabalho, que limita, em cada contexto, o conjunto de informações necessárias à conclusão de um trabalho. Mautz (1980), tratando da sua teoria do conhecimento, a respeito da utilização de resultados bem sucedidos, afirma:

Muitas vezes enfrentamos problemas de julgamento que de momento são quase insolúveis, mas que fatos posteriores esclarecem satisfatoriamente. Por exemplo, decidir sobre a possibilidade de reconhecimento de valores realizáveis logo após a data da venda é realmente difícil; mas após a decorrência de alguns meses, ou anos, estaremos em melhores condições de julgar se essas vendas resultaram em valores de boa liquidez. As ações provocam conseqüências; se nos for dado tempo de esperar por elas obteremos provas sobre a prudência e a validade da ação. (MAUTZ, 1980 , p. 83 , grifo nosso).

Portanto, a construção de um julgamento requer tempo e experiência, condições também necessárias ao reconhecimento de um elemento possuidor da característica propriedade à formação de uma opinião. 


\subsection{Suficiência}

A Norma Brasileira de Contabilidade Técnica - NBC T 11.3, que trata dos papéis de trabalho, determina que o auditor deverá promover anotações relativas ao planejamento de auditoria, à natureza, à oportunidade e à extensão dos procedimentos aplicados, aos resultados obtidos e às suas conclusões sobre as evidências encontradas.

A mesma norma diz que o profissional deve emitir seu juízo acerca das questões significativas e de difícil julgamento.

11.3.2.1. ...O auditor deve registrar nos papéis de trabalho informação relativa ao planejamento de auditoria, a natureza, a oportunidade e a extensão dos procedimentos aplicados, os resultados obtidos e as suas conclusões da evidência da auditoria. Os papéis de trabalho devem incluir o juízo do auditor acerca de todas as questões significativas, juntamente com a conclusão a que chegou, inclusive nas áreas que envolvem questões de difícil julgamento. (CFC, 2006).

Chama atenção a inclusão na definição dos elementos identificados como significativos e de difícil julgamento profissional, caracterizando o conceito de suficiência. Analisar a suficiência envolve pertinência, regularidade e representatividade; e numa escala de prioridade, mais representatividade (materialidade).

A materialidade não constitui um princípio contábil, mas acompanha a definição de preceito e regra técnico-comportamental exposta na Resolução n. ${ }^{\circ} 774 / 94$, emitida pelo CFC. Estas características dão suporte à existência de conceitos e situações híbridas que envolvem aplicação dos Princípios Fundamentais de Contabilidade - CFC, harmonização em função do objeto de trabalho e representatividade dos elementos qualitativos e quantitativos que dão suporte à formação de uma opinião. A figura a seguir delimita esta relação:

\section{Figura 2 - Caracteres de suportes para a formação da opinião}

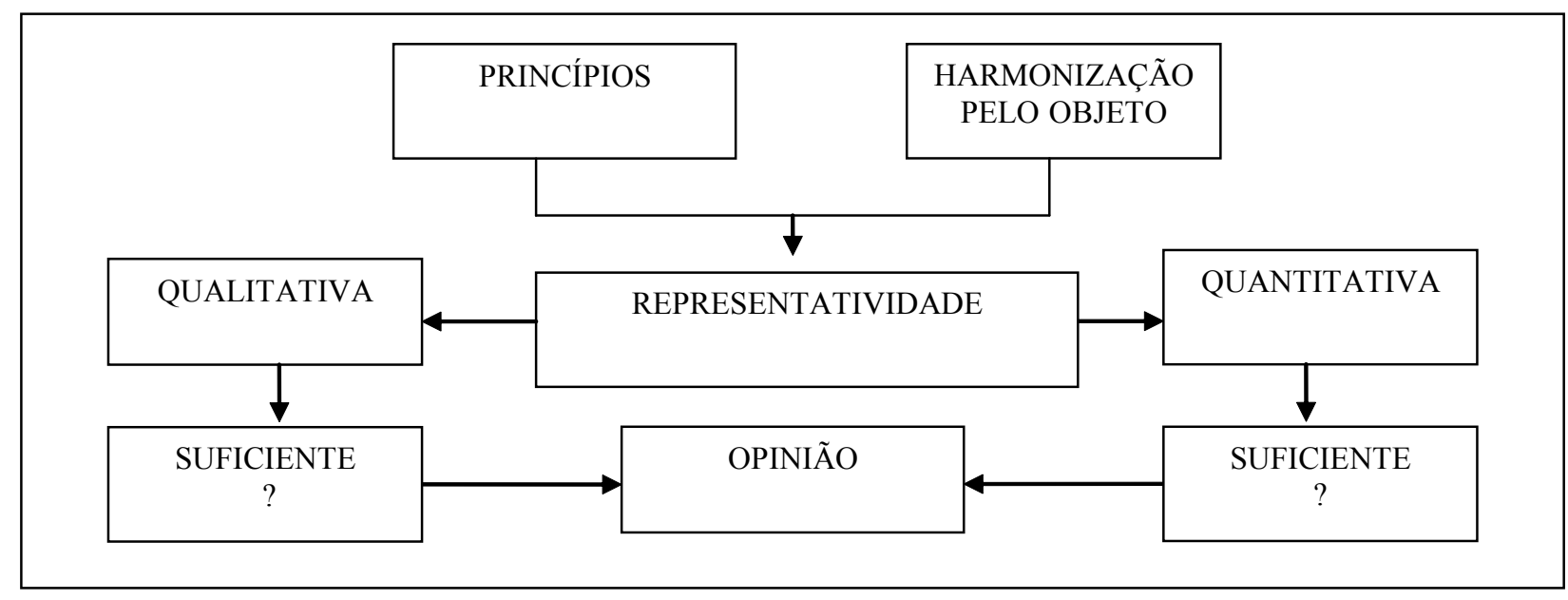

Elaborado pelo autor. 
A figura não se traduz numa tentativa de estabelecer um novo norte sobre o desenho geral de um trabalho de auditoria, mas antes num complemento ao definido por Mautz (1980) e corroborado por Magalhães, Lunkes e Muller (2001) e Basso (1989) como processo de formação da opinião do auditor.

O processo apresentado por Mautz (1980) comporta cinco pontos mínimos:

1. A identificação das informações a serem examinadas;

2. A avaliação da relativa importância das informações;

3. O recolhimento das informações ou provas necessárias sobre as afirmações, a fim de possibilitá-lo a dar um parecer bem fundamentado;

4. Avaliação das provas, quanto a validade ou não, se adequada ou não, se suficiente ou não; e,

5. Formulação da opinião quanto a exatidão das informações examinadas;

Esta representação está conceitualmente contida no primeiro ponto apresentado na figura 1. Do recolhimento da prova à decisão final por parte dos usuários, surgem no processo um conjunto de gráficos e subgráficos que se dividem a cada estágio de verificação. Alguns pontos podem ser inferidos a partir desta afirmação:

- A suficiência de uma informação, dado ou atributo traduz adequacidade, mas a recíproca não é verdadeira. Um dado adequado não significa completeza para defini-lo como suficiente;

- A suficiência de uma informação, dado ou atributo traduz validade, mas a recíproca também não é verdadeira. Um dado pode ser válido para identificar uma operação, mas pode não ser suficiente para provar sua completeza e relativa verdade;

- Validade e adequacidade estão, obrigatoriamente, atreladas à suficiência, mas estas características, quando identificadas isoladamente, por si só não tornam um elemento suficiente.

O que define, portanto, a suficiência de uma prova é o somatório da sua adequacidade, validade e materialidade inerente ao que está sendo objeto de exame, condições que não se distinguem em nível de importância ao conceito de propriedade, mas, antes, complementa. Por isso a informação de processo construído, envolvendo os característicos propriedade e suficiência.

\section{CONSIDERAÇÕES FINAIS}

Discutir prova auditorial significa analisar uma gama de conceitos subjetivos. Neste trabalho procurou-se apresentar a prova como o elemento principal no proces- 
so de formação da opinião do auditor, e de que forma esta opinião repercute ante seus usuários.

A temática abordada constitui-se terreno árido no campo acadêmico por comportar algumas linhas de pensamento não enfatizadas neste trabalho, a exemplo das definições e conceituações aceitas na legislação americana adotadas pela Federal Internacional de Contadores - IFAC e United States General Accounting Office - GAO, que apresentam elementos complexos em comparação às normas e princípios brasileiros. Essa constatação apenas reforça a necessidade de se aprofundar a discussão sobre a propriedade e suficiência da prova, apresentada neste ensaio como o principal ponto de formação de uma opinião, que vem a se constituir num poder racional e legal do profissional de auditoria. Esse poder assume características específicas diante do domínio que o profissional tem de uma especialidade técnica necessária a determinados grupos de usuários, provocando, nesses usuários, níveis de dependência em função desse domínio.

Este ensaio procura colaborar com a discussão das temáticas apresentadas, mas torna-se importante destacar a necessidade de se aprofundar a pesquisa sobre os temas envolvidos, comparando as abordagens diante da tentativa de harmonização das normas internacionais de contabilidade, bem como sobre os aspectos de intensidade e disseminação da prova ante sua propriedade e suficiência.

Destaca-se, por fim, a idéia de complementar essa discussão apresentando um desenho ao que já é exposto na literatura, sem a pretensão lúdica de encerrá-la.

\section{REFERÊNCIAS}

ALMEIDA, Marcelo Cavalcanti. Auditoria: um moderno curso e completo. 6. ed. - São Paulo: Atlas, 2003.

ATTIE, William. Auditoria: conceitos e aplicações. 3.ed. - São Paulo: Atlas, 1998.

BACHARACH, S. B., LAWLER, E. J. Power and politics in ornganizations. San Francisco, Jossey-Bass, 1980.

BASSO, Irani Paulo. Iniciação à Auditoria (Coleção administração e contabilidade). $2^{\mathrm{a}}$.ed ljuí: Liv. Unijuí, 1989.

BOYNTON, William C., JOHNSON, Raymond N., KELL, Walter G.; Tradução Jose Evaristo dos Santos. - São Paulo: Atlas, 2002. 
BORGES, Erivan Ferreira. Comprometimento e ética profissional: um estudo de suas relações junto aos contabilistas da cidade de Natal/RN. Dissertação de Mestrado. Natal: PPGA/UFRN, 2005.

CONSELHO FEDERAL DE CONTABILIDADE. Princípios fundamentais de Contabilidade e Normas Brasileiras de Contabilidade de auditoria e Perícia: CFC, 2006.

. Princípios fundamentais e normas brasileiras de contabilidade. Conselho Federal de Contabilidade. Brasília: CFC, 2006.

COOK, John William \& WINKLE, Gary M. Auditoria: filosofia e técnica. Tradução de Sônia Schwartz. São Paulo: Saraiva, 1983.

DIZARD, Wilson P. The coming information age. New York : Longman, 1982. 213 p.

FERREIRA, Aurélio Buarque de Holanda. Novo Aurélio século XXI: o dicionário da língua portuguesa. $3^{a}$. ed Rio de Janeiro: Nova Fronteira,1999.

FOUCAULT, Michel. Microfísica do poder; organização e tradução de Roberto Machado. 24a . ed. Rio de Janeiro: Edições Graal, 2007.

FRANCO, Hilário; MARRA, Ernesto. Auditoria Contábil, 2.ed. - São Paulo: Atlas, 1996.

HALL, Richard H. Poder e impactos do poder. São Paulo: Printice Hall, 2004.

LISBOA, Lázaro Plácido e et al.. Ética Geral e Profissional e contabilidade. São Paulo: Atlas, 1997.

MAGALHÃES, Antônio de Deus F.; LUNKES, Irtes Cristina; MULLER, Aderbal Nicolas. Auditoria das Organizações: metodologias alternativas ao planejamento e à operacionalização dos métodos e das técnicas. São Paulo: Atlas, 2001.

MAUTZ, Robert Kuhn. Princípios de auditoria; tradução de Hilário Franco. $3^{a}$. ed. São PauIo, Atlas, 1980.

MINTZBERG, H. El poder en la organización. Barcelona: Editorial Ariel S.A., 1992. 
MORGAN, Gareth. Imagens da organização. Tradução de Cecília Wiltaker Bergamini, Roberto Coda: São Paulo: Atlas, 1996.

SÁ, Antônio Lopes de. Curso de auditoria. 9. ed. - São Paulo: Atlas, 2000.

. Ética profissional. 4ª ed São Paulo: Atlas, 2001.

SILVEIRA, Henrique Flávio Rodrigues da. Um estudo do poder na sociedade da informação. Ci. Inf. v.29 n.3 Brasília set./dic. 2000.

SOUZA, Eloisio Moulin, BIANCO, Mônica de Fátima, MACHADO, Leila Domingues. In: ENANPAD 30, Salvador. Anais do 30 Encontro da Anpad - Organizações - CD-ROM, 2006.

WEBER, Max. The Theory of social and Economic Organization. London: Oxford University Press, 1947. 